\title{
A tribute to John G. Bartlett, MD (1937-2021)
}

\author{
Thomas C. Quinn ${ }^{1,2}$ and Joel N. Blankson ${ }^{1}$ \\ 'Division of Infectious Diseases, Johns Hopkins University School of Medicine, Baltimore, Maryland, USA. ²Division of Intramural Research, National Institute of Allergy and Infectious Diseases (NIAID), NIH, \\ Bethesda, Maryland, USA
}

A true giant in the field of infectious diseases and HIV/AIDS care, John G. Bartlett, MD, passed away on January 19, 2021 (Figure 1). His absence will be felt by many, and he has left an indelible mark on the field of infectious diseases for many years to come. Known for his round-the-clock work ethic, starting at 4 am and working late into the evening, John had a grasp for what was important and timely in our field. He is well known for his early discovery of Clostridium difficile as the cause of antibiotic-associated colitis, his insights and treatment of anaerobic abdominal and pulmonary infections, community-acquired pneumonia, bioterrorism, and emerging and reemerging infectious agents, from anthrax to Zika. At Johns Hopkins, John will always be known best for his work in the HIV/AIDS field. He was the driving force for creating a dedicated HIV inpatient ward and an HIV/hepatitis outpatient clinic, which has now been named after him as the John G. Bartlett Specialty Clinic, known for providing the best care for patients with HIV and hepatitis infections.

John was born in Syracuse, New York, on February 12, 1937. He attended and graduated from Dartmouth College in 1959, and obtained his medical degree in 1963 from the State University of New York (SUNY) College of Medicine in Syracuse. He pursued training in internal medicine at the Peter Bent Brigham Hospital in Boston and at the University of Alabama in Birmingham, where he developed an initial interest in cardiology. His clinical training was interrupted when John served a two-year obligation in the Army Medical Corps in Vietnam from 1965 to 1967 . This

experience resulted in a pivotal change in John's medical career as he discovered a fascination with infectious diseases while in Vietnam. He said, "you can look in the microscope and see the enemy" (Richard Chaisson, personal communication).

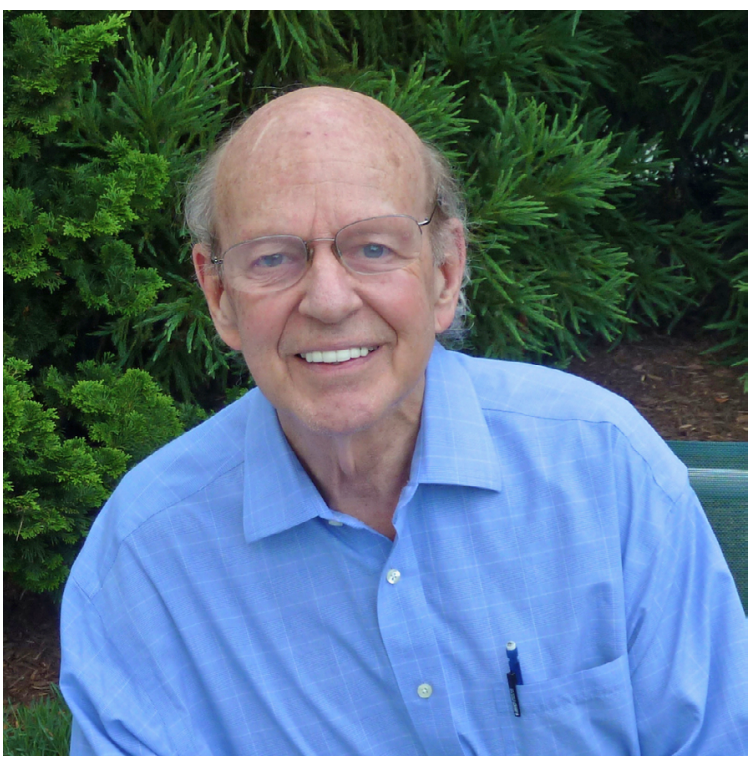

Figure 1. John G. Bartlett, MD. Image credit: Thomas C. Quinn.

ium difficile caused pseudomembranous colitis (3-7). They showed that intercaecal injection of stool from patients with pseudomembranous colitis would induce enterocolitis in hamsters. Furthermore, they were able to isolate Clostridium difficile from the stool of these patients and show that intercaecal injection of the cultured bacteria recapitulated the disease in hamsters (7). Diagnostic tests and effective therapy for this disease were eventually developed based on John's landmark study (7-10).

After holding faculty positions at the University of California, Los Angeles, and subsequently at the Tufts-New England Medical Center, he was recruited in 1980 to become Director of the Johns Hopkins University School of Medicine Division of Infectious Diseases, and was appointed as the Stanhope Bayne-Jones Professor of Medicine. In the ensuing 26 years, the division grew from just three full-time staff members to one of Johns Hopkins' largest divisions, with a roster of 55 faculty members, a staff of 177 , and an annual research budget of $\$ 40$

Once he completed his military service, he dropped his pursuit of cardiology and initiated his study of infectious diseases at the University of California at Los Angeles with Sydney Finegold, an expert in anaerobic infections. Under the mentorship of Sydney, and subsequently, Shelley Gorbach, John's research flourished, and he truly exemplified a multidimensional physician-scientist. His initial research was on diagnosis and treatment of pulmonary and abdominal anaerobic infections $(1,2)$. In 1978, John and his collaborators performed definitive studies that proved that Clostrid- million (10). In his own unique style, John encouraged the growth of the division and promoted the development of internationally renowned research programs in HIV/ AIDS, tuberculosis, viral hepatitis, sexually transmitted diseases, hospital epidemiology and infection control, antibiotic stewardship, enteric infections, and transplant/ oncology infectious diseases. Most of these programs sprang up from fellows trained under Bartlett and were inspired to remain in the division to tackle the next big thing in infectious diseases (11).

In retrospect, John Bartlett arrived at Hopkins just as the AIDS epidemic was being identified $(12,13)$. He recognized the potential escalation of this deadly disease in the United States and, along with 
epidemiologist B. Frank Polk, cofounded the country's second HIV/AIDS clinic, which rapidly became one of the world's preeminent HIV/AIDS treatment centers. By the time he stepped down in 2006, the division was treating more than 5,100 patients annually with the latest treatment regimens, many of which he helped validate through clinical trials. In addition to administering trials of potential medications for patients with HIV/AIDS, John Bartlett will be remembered for the compassion he showed for these patients. His dedication to the HIV field occupied most of his time, writing multiple papers and textbooks as well as speaking on the topic. He emerged early in the epidemic as one of the leading experts in the treatment of HIV/AIDS, and he chaired multiple national committees that developed guidelines on HIV and opportunistic infections. The Bartlett Pocket Guide to HIV/AIDS Treatment (14) and The Medical Management of HIV Infection (15), now in their 19th and 17th editions, respectively, remain the definitive textbooks on HIV clinical care.

Although he stopped his lab-based research when he assumed the position of chief of infectious diseases, his appreciation of lab-based research never ceased, and he inspired many generations of physician-scientists. He was revered but not feared by the house staff and fellows. Rounding with him was always an incredible experience; his knowledge of the literature was encyclopedic in nature but more importantly he would tell trainees what wasn't known and would encourage them to pursue these areas of research. $\mathrm{He}$ inspired many trainees to go from bedside to bench and back in an effort to improve patient care. Dr. Cynthia Sears, who Bartlett recruited to be the first fellowship director, describes his impact: "He was a force in the development of translational science: the clinic as a laboratory and connecting the laboratory to the clinic" (Cynthia Sears, personal communication).

A true visionary, he was an extraordinary investigator, clinician, and educator. As President of the Infectious Diseases Society of America (IDSA), John profoundly shaped the direction of infectious diseases. Well known as a skilled speaker and writer, John Bartlett was presented with the Alexander Fleming Award for lifetime achieve- ment from the IDSA, and the Maxwell Finland award from the National Foundation for Infectious Diseases for his groundbreaking research and treatment accomplishments. He authored more than 500 original papers, 330 book chapters, and 14 books. A Master of the American College of Physicians, and a member of the National Academy of Medicine, he received multiple other awards from multiple medical societies. He was a brilliant lecturer who could explain complicated infectious disease concepts to scientists, clinicians, and lay people, and was so well known over the years for his "Top Ten" and "Hot Topic" lectures in infectious diseases (16-19).

There have been many quotes describing the personality of John Bartlett, but one of the most appropriate is by Tony Fauci of the NIAID: "Even though there are very few, if any, people in modern times who are world experts in as many areas of medicine, John Bartlett is one of the kindest, most gregarious people you will ever meet - he has a way of making everyone around him feel comfortable. He also has an amazingly positive outlook on life - for him, life is a joy. He is a legend in the field of infectious diseases, but, above all, he is an outstanding human being" (20).

Dave Thomas, his successor as Division Director, stated, "He was one of those people whose impact was large ... His legacy comes down to his ability to see things clearly a year before anyone else could see it. He was that kind of person, who saw ahead, and had that ability to encapsulate important elements and make them very understandable. It was like bringing science to poetry" (D. Thomas, personal communication). William Bishai at Johns Hopkins describes how John Bartlett's vision impacted his research career starting in 1994 when Bartlett suggested that he not study Haemophilus influenzae, but rather focus on another pathogen. John said, "Read the newspapers, haven't you seen that tuberculosis is coming back in New York City?" (William Bishai, personal communication). Stuart Ray stated that John Bartlett, "had an uncanny skill for asking probing questions that were highly motivating for developing deeper knowledge. His well-informed but playful enthusiasm was infectious" (S. Ray, personal communication). Chloe Thio echoes this sentiment: "What struck me about him was his ability to discuss labbased studies to support clinical decisions and I think that helped me realize the power of the lab to answer clinical questions. He made me realize that questions that came up clinically could be studied in the lab and I have tried to embody that idea throughout my career" (C. Thio, personal communication). Yuka Manabe points out that, "linking clinicians with bench scientists to solve problems of fundamental importance is an area where Dr. Bartlett excelled" (Yuka Manabe, personal communication).

Henry Masur of the NIH stated, "To me, John is the essence of what a professional colleague should be in any field, and the prototype of an academic physician. He has always been positive and supportive of his colleagues of all ages, and usually finds the best in people rather than dwelling on their deficiencies. He is fascinated by the entire field of infectious diseases, not just his own niches. He wants his trainees, his colleagues, his institution, and all of medical science to be successful" (18). Thomas Slama stated that, "His footprint on the field of infectious diseases and healthcare is deep and likely unmatched. His problem-solving abilities, uncanny ability to predict and solve the problems on the horizon, his organization and communication skills coupled with his unbridled energy and passion truly make him one of a kind. What an honor to have known him" (18).

Although we focus here on his academic career, John was also fully dedicated to the precious time he spent with his family. As a true renaissance person, John was a very talented artist, and he once took a sabbatical in Paris to hone his skills in painting portraits and still-lifes. His wife of 50 years, Jean Scott, a registered nurse, died in October 2020, just three months before John's death. John is survived by his five children and eight grandchildren.

Address correspondence to: Thomas C. Quinn, 600 N. Wolfe Street, Rangos Building Suite 531, Baltimore, Maryland 21287, USA.Phone: 410.955.7635; Email:tquinn2@ jhmi.edu. Or to: Joel N. Blankson, Johns Hopkins University, 855 N. Wolfe Street, Rangos Building Suite 552, Baltimore, Maryland 21205, USA. Phone: 410.502.9920; Email:jblanks@jhmi.edu. 
1. Bartlett JG, et al. Treatment of anaerobic infections with lincomycin and clindamycin. NEngl J Med.1972;287(20):1006-1010.

2. Bartlett JG, et al. Percutaneous transtracheal aspiration in the diagnosis of anaerobic pulmonary infection. Ann Intern Med. 1973;79(4):535-540.

3. Bartlett JG, et al. Clindamycin-associated colitis due to a toxin-producing species of Clostridium in hamsters. JInfect Dis. 1977;136(5):701-705.

4. Bartlett JG, et al. Antibiotic-associated pseudomembranous colitis due to toxin producing clostridia. N Engl JMed. 1978;298(10):531-534.

5. Bartlett JG, et al. Will the real Clostridium species responsible for antibiotic-associated colitis please step forward? Lancet. 1978;1(8059):338.

6. Tedesco FJ, et al. Oral vancomycin for antibioticassociated pseudomembranous colitis. Lancet. 1978;2(8083):226-228.

7. Karakousis P. Follow your gut: The illustrious career of John G. Bartlett, MD. Pharos.
2019; Spring Issue:17-23.

8. Chang TW, et al. Cytotoxicity assay in antibiotic-associated colitis. J Infect Dis. 1979;140(5):765-770.

9. Bartlett JG, et al. Symptomatic relapse after oral vancomycin therapy of antibiotic-associated pseudomembranous colitis. Gastroenterology. 1980;78(3):431-434.

10. Bartlett JG. Clostridium difficile infection: historic review. Anaerobe. 2009;15(6):227-229.

11. Auwaerter PG, et al. John G. Bartlett: a transformative, visionary leader of Johns Hopkins Infectious Diseases. Clin Infect Dis. 2014;59(Suppl 2):S61-S62.

12. Centers for Disease Control. Pneumocystis pneumonia-Los Angeles. MMWR Morb Mortal Wkly Rep. 1981;30(21):250-252.

13. Centers for Disease Control. Kaposi's sarcoma and pneumocystis pneumonia among homosexual men-New York City and California. $M M W R$
Morb Mortal Wkly Rep. 1981;30(25):305-308.

14. Bartlett JG, et al. The Bartlett Pocket Guide to HIV/ AIDS Treatment. Westview Urgent Care MediCenter; 2019.

15. Bartlett JG, et al. Bartlett's Medical Management of HIV Infection. Oxford University Press; 2019.

16. Spellberg B, et al. The future of antibiotics and resistance. N Engl JMed. 2013;368(4):299-302.

17. Spellberg B, Gilbert DN. The future of antibiotics and resistance: a tribute to a career of leadership by John Bartlett. Clin Infect Dis. 2014;59(Suppl 2):S71-S75.

18. Nielsen TB, et al. Sustainable discovery and development of antibiotics - is a nonprofit approach the future? $\mathrm{NEnglJ} \mathrm{Med}$. 2019;381(6):503-505.

19. Henderson DA. John Bartlett and bioterrorism. Clin Infect Dis. 2014;59 suppl 2:S76-S79.

20. Lorber B. John Bartlett: appreciation \& celebration. Clin Infect Dis. 2014;59(Suppl 2):S63-S65. 